\title{
CARDIAC MEMBRANE POTENTIALS RECORDED FROM THE INJURED VENTRICULAR CELLS OF DOGS
}

\author{
GOU UEDA* \\ Department of Physiology, Faculty of Medicine, University of Tokyo, Tokyo
}

Schütz (1), Jochim, Katz and Mayne (2) and many other workers investigated the monophasic cardiac action potentials recorded as a potential difference between the normal and the injured parts of the heart, but such a method of study cannot reveal the fundamental properties of cardiac cells, because the potentials thus recorded are the sum total of the phenomena taking place in a great numbers of normal as well as more or less injured muscle fibers. However, the microelectrode of Ling and Gerard (3) offered a very effective technique for examining the cellular potentials. This technique has been utilized by Weidmann (4), Brooks, Hoffman et al. (5), Trautwein (6), Woodbury (7), Matsuda, Hoshi and Kameyama (8), Sano (9) and others, and abundant results of significance have been so far reported concerning the cellular potentials of cardiac muscle. In this article, the author studied some electrical properties of the cells in and around the injured region by means of the microelectrode technique. Strictly speaking, it may be said, that the impalement with a microelectrode causes, more or less, an injury to the cell, and even the excision of the heart muscle brings about a state different from the normal. In this report, however, a certain more drastic and distinct injury was given to the muscle so as to produce the definite effects of injury. This report does not concern itself with "injury potential" between the normal and the injured region, but with the resting and action potentials and other electrophysiological properties of the individual injured cells.

Hitherto no investigation has been found reported in such a sense (10). A part of this study was communicated in the 35th Congress of the physiological Society of Japan (11).

METHOD

Experimental Animal. Dogs with body weight of 6 to $7 \mathrm{~kg}$. were used. Mainly $30 \mathrm{mg}$. pro kg. of Mintal (Sodium-Pentobarbital) was injected intraperitoneally as an anaesthetic agent. The chest was opened by median incision under the artificial respiration. The heart was excised and washed immediately with warmed $\left(37^{\circ} \mathrm{C}\right.$.) Tyrode's solution saturated with oxygen. The samples

Received for publication March 28, 1959.

* 上田五雨 
(the size of approximately $3 \mathrm{~cm}^{2}$ ) were prepared from the free wall mainly of the right ventricle. These were kept immersed in the $\mathrm{O}_{2}$-saturated Tyrode's solution. In order to minimize the possible, transient effects caused by the attack of operation, samples were used after over one to several hours' preservation or even after having been kept in a refrigerator at $2-3^{\circ} \mathrm{C}$. for 24 hours or more. It has been reported elsewhere that the specimens thus preserved recover its normal electrophysiological properties quite satisfactorily on rewarming (12).

The specimen of the cardiac muscle was placed in a bath made of lucite and the Tyrode's solution in the bath was continuously circulated through the thermostat, and saturated with bubbling of $\mathrm{O}_{2}$. The temperature in the bath was kept constant at $36^{\circ} \mathrm{C}$.

Microelectrode. The electrodes used had resistances from 5 to $17 \mathrm{M} \Omega$. They were not boiled, and $3 \mathrm{M}-\mathrm{KCl}$ was filled with a special injection needle from thick end (13).

Arrangement of the electrical circuits. The circuit construction is about the same as by Sakurai et al. (14) and is shown diagrammatically in fig. 1. The preamplifier consists of $12 \mathrm{AU} 7$ (cathode-follower), $12 \mathrm{AT} 7$, and $6 \mathrm{SN} 7$.

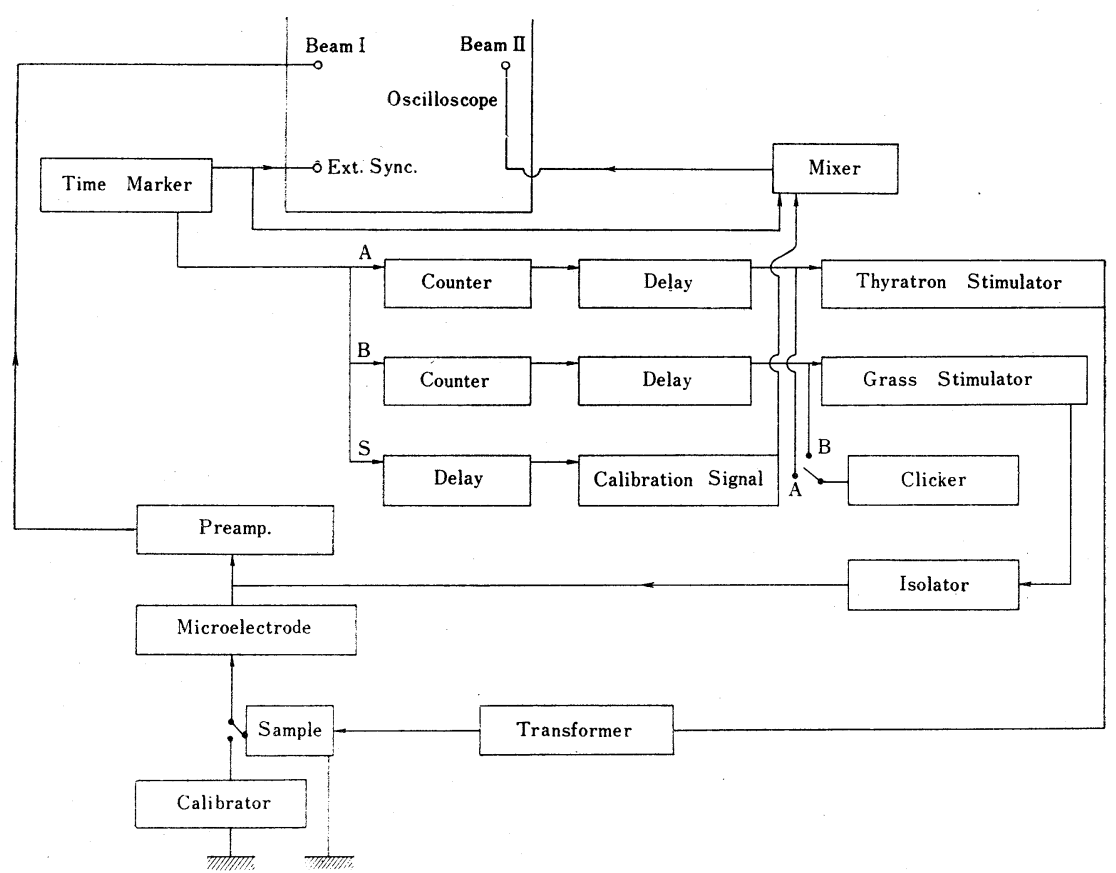

FIG. 1. Block diagram of the electronic circuit for studying the cardiac membrane potential. 
Method of inducing experimental injury. Three types of method were adopted. 1) The surface of the heart was compressed forcibly to destroy the muscles mechanically with one end of a capillary glass tube for microelectrode. In spite of the simplicity of this technique, this method is very certain in producing the effect, 2) a sustained compression was applied transversely on the surface of the sample of the heart muscle with a thread, 3) a local burn was produced on the surface of the sample by a heated wire, after temporarily discarding Tyrode's solution. Fresh Tyrode's solution was let to irrigate the sample which had undergone burn.

Driving of the heart. Stimulus electrodes of silver have a diameter of about $0.5 \mathrm{~mm}$. Two of them were inserted on the sample. As a stimulus, a discharge current of a thyratron was taken out of the one end of the cathode load through an inductorium, the secondary coil of which was connected with the electrodes. Standard driving rate was fixed to one per $700 \mathrm{msec}$.

\section{RESULTS}

\section{Action potentials of the cardiac cells near the injured region}

When the endocardium was injured by a capillary glass tube with an outer diameter of 2 to $3 \mathrm{~mm}$., the neighbourhood cells showed an action potential of the injured type. The nearer to the center of injury, the smaller was the resting potential $(\mathrm{RP})$.

Results are shown in fig. 2. In this case, the normal membrane potential showed, as in fig. $2, A$, about $100 \mathrm{mV}$ of $\mathrm{RP}(100 \mathrm{mV}$ was indicated by a point of the left lower part. The zero level was adjusted to the time base). The duration of the action potential (AP) lasted about $300 \mathrm{msec}$, and the remarkable plateau appeared at the repolarisation phase. When the central part of this sample was injured by a glass tube, the grade of injury decreased gradually as indicated in $B, C, D, E, F$, with an increasing distance from the injured spot. The AP of $D$ and $E$ were recorded at the same place, the former from the first layer, and the latter from the second layer. $G$ was recorded from the cell opposite to the driving electrode as regards the injured spot. It is adjacent to the margin of the injured region. The shape of AP is not always the same even though the distance is equal. This suggests that the heart muscle is not necessarily to be considered as a homogeneous structure. Fig. 2 indicates such an example.

Similar injury with a diameter of about $3 \mathrm{~mm}$. was applied locally by burning. Immediately after that, the spike type AP and the dome type AP appeared alternately. The former disappeared gradually, and the plateau in the latter type came markedly to the fore. This transient process was photographed and shown in fig. $3, B$. After a while, the notch of AP, characteristic to the epicardial layer cell, appeared. These are shown in fig. 3.

When compressed with a thread, the cells near the pressed region showed a plateau-less triangular AP, which was somewhat different from the case of glass tube compression, or burn. 


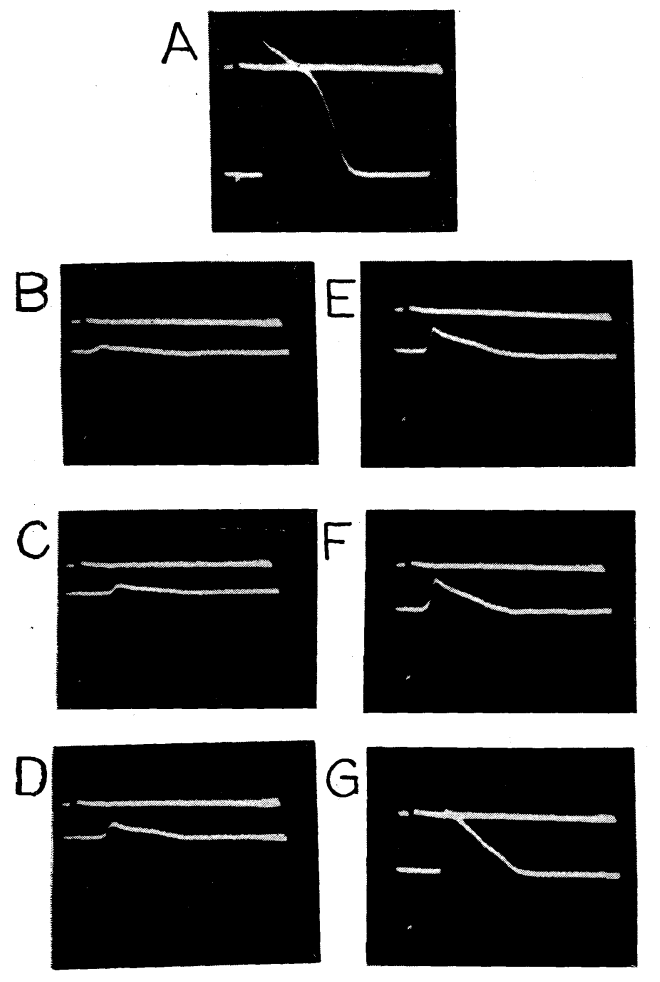

FIG. 2. The AP's of injured cells, at various distances from the injured spot.

The interval between the two small time marks is $10 \mathrm{msec}$, and between two large time marks $50 \mathrm{msec}$. The calibration mark of $100 \mathrm{mV}$ was inserted into the left lower part as a white point.

$A$. The normal control.

$B .5 \mathrm{~mm}$., from the injured site.

C. $7 \mathrm{~mm}$.

D. $10 \mathrm{~mm}$. The 1st layer of the endocardium.

E. $10 \mathrm{~mm}$. The 2 nd layer of the endocardium.

F. $20 \mathrm{~mm}$.

G. $5 \mathrm{~mm}$. in opposite direction.
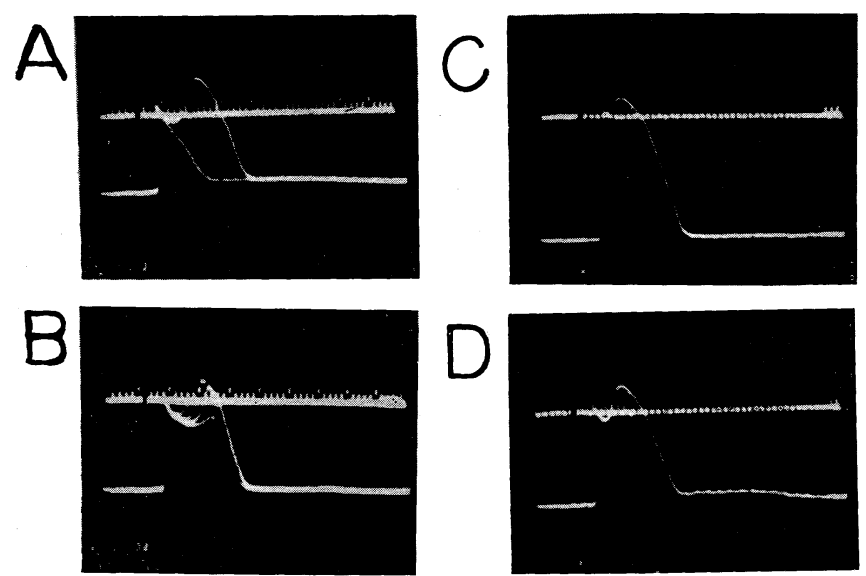

FIG. 3. The right ventricular free wall. These AP's are the record of the epicardium. Local burn with a diameter of about $3 \mathrm{~mm}$. was applied :

$A$. Immediately after burning. Spike and dome type wave appeared transiently.

$B$. AP's which appeared after the " $A$ " and were superposed.

C. The almost normal form.

$D$. The characteristic epicaridal form. 


\section{The relation between $R P$ and other electrophysiological properties}

From the foregoing description, it was manifested that the RP's of the cell near the injured spot were diminished and AP's had a characteristic form. Accordingly the relations between RP and overshoot (OS), RP and upstroke velocity, $\mathrm{RP}$ and AP duration were measured with various examples and plotted to the graphs. Those data will be shown in the next graphs. The relation between RP and OS is shown in fig. 4, which indicates that the decrement of OS is roughly proportional to RP and that OS often takes a negative value when RP is less than $60 \mathrm{mV}$. This relation shows a trend similar to the data taken from Purkinje fiber by Weidmann. In our case, the cells are not always Purkinje fibers, and hyperpolarisation was not caused by direct current application. The experimental conditions are more complicated. That is why our data have more variance than Weidmann's one (15).

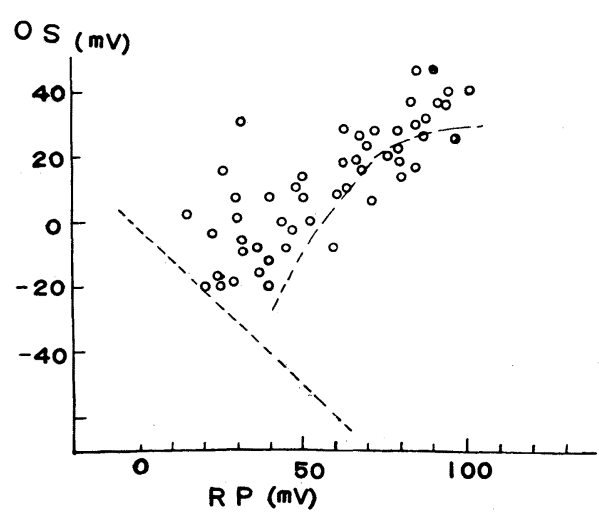

FIG. 4. The relation between overshoot and repolarisation. To the cells, measured in this case, mechanical injury was applied by a glass tube.

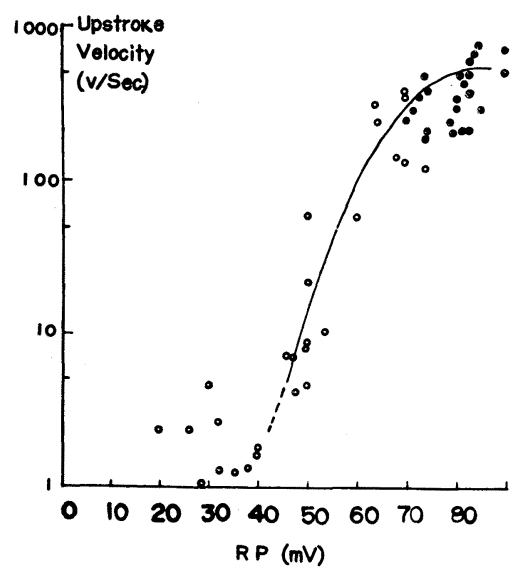

FIG. 5. The relation between upstroke-velocity and RP. The solid circles indicate normal cells. The open circles indicate injured cells.

$\mathrm{RP}$ was proved to be roughly proportional to the upstroke veloity. This relation is demonstrated in fig. 5. In the range of 20 to $90 \mathrm{mV}$ of $\mathrm{RP}$, the rise velocity varied from $1.02 \mathrm{~V} / \mathrm{sec}$. to $345 \mathrm{~V} / \mathrm{sec}$. The scale of the ordinate was plotted logarithmically in order to distinguish the rise velocities of the depolarised states in detail.

Finally, the relation between RP and AP-duration was compared for the normal and injured cells, and the result was shown in fig. 6. This has proved no special relationship, and AP-durations of the cells were indifferent to RP values. However, it is noticed, that usually the normal cells have longer AP. durations than the injured cells, and have less variance as for their values. This fact is very important, for it is the very reason why the ventricular gradient increases in the case of injury or disease of the heart. In other words, ventricular gradient means the quantity which is related to the local differences 


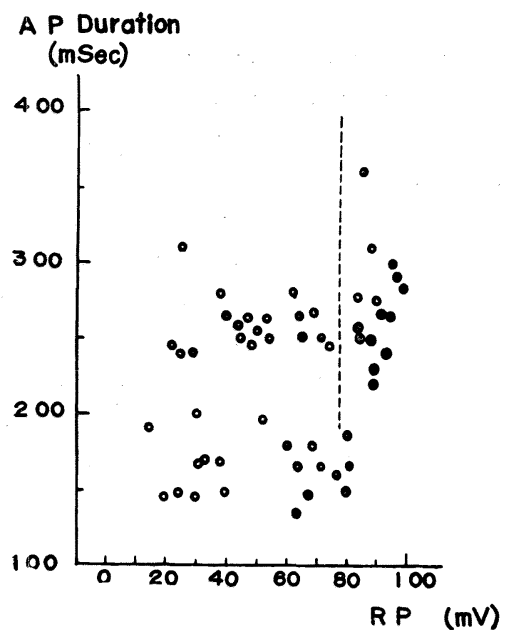

of the recovery of excitation according to Burger (16), and so the increased variance of above described AP-duration in an injured state must be considered to be an important factor of the increased ventricular gradient. However, Burger's theory on the ventricular gradient is not so strict, so that this proof may be only a kind of indirect approach.

FIG. 6. AP-Duration-RP relationship.

The dotted vertical line divides the normal group from the injured group.

\section{Direct current application}

We noticed, that one important parameter of a cardiac injury was the values of RP which was easily measurable. Therefore, we have attempted to hyperpolarize or depolarize the cell membrane during a brief period, in order to test whether the wave form of the injured cell recovers to the normal form or not, when RP's were altered to various extents. The results indicated that the parameters of wave forms such as rising velocity and OS of AP were not restored to normal by the temporary polarization with application of a short current pulse.
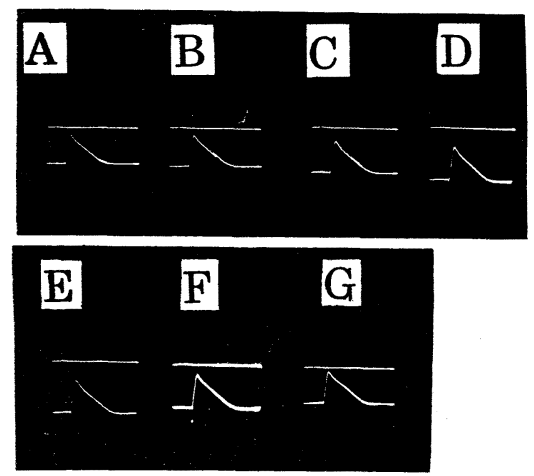

FIG. 7. Direct current application.

$A$. Anodic $0.1 \times 10^{-8} \mathrm{~A}$

B. $\quad$ " 0.3

C. $\quad " \quad 0.5$

D. $\quad$ " 0.7

E. Cathodic $0.1 \times 10^{-8} \mathrm{~A}$

F. " $\quad 0.3$

G. $\quad$ " 0.5

By the application of currents for longer periods such as 5 to 10 minutes neither restoration of OS nor of rise velocity was noticed in some cases, though a slight deformation of the AP was noticed in other cases. After all, we cannot always produce a recovery of some parameters by means of the external hyperpolarization. In these experiments, artefact due to the resistance of the microelectrode, when direct current was applied, was cancelled by a bridge method, which will be explained later. The current was limited to the lesser level so 
that it does not cause any change to the electrode behavior (17). The records of the injured cell potential, which contain no change in wave forms after 10 minutes of polarization, were omitted here to cite.
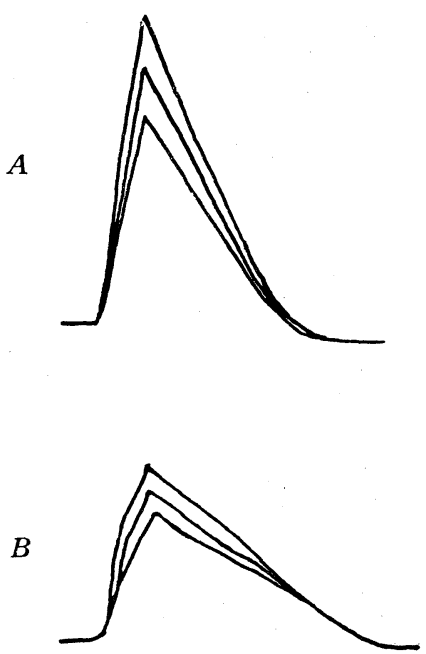

FIG. 8. About 10 minutes of DC application. Only the examples of the deformed action potentials were shown here. The ordinate was enlarged in order to exaggerate the relative changes fully.

$A$ : The lower curve: the control.

The middle one: after 5 minutes of anodic polarisation.

The upper one: after 10 minutes.

$B$ : The upper curve: the control different from $A$.

The middle one: after 5 minutes of cathodic polarisation.

The lower one: after 10 minutes.

\section{Membrane resistance}

From the foregoing findings, we noticed the significant change of RP caused by injured effects, but pointed out the fact also, that the RP was not the mere parameter for measuring the degree of injury. As one of the other factors, Osterhout (18) considered the electrical resistance as a very important parameter of injury as for the cells of a marine plant, Laminaria. The author applied this idea for measuring the injury of each cardiac cell, and attempted to know, whether the membrane resistance rises or decreases. This trial was started with an intention of qualitative experiment.

To measure the membrane resistance the bridge compensation method after Yamanaka (19) was followed, with slight modification of arm resistance values to $10 \mathrm{M} \Omega: 1 \mathrm{M} \Omega$ instead of $100 \mathrm{M} \Omega: 10 \mathrm{~K} \Omega$. In addition $100 \Omega$ was inserted in the arm for test resistance. A counter-electromotive force was applied in order to cancel RP. For instance, when $1 \mathrm{~mA}$ is applied to the $100 \Omega$ it produces $100 \mathrm{mV}$. For this purpose, a part of the calibration circuit for the membrane potential measurement was utilized.

The possible change of the electrical resistance of a microelectrode when direct current was applied, had been pointed out by many investigators previously. However, the resistance of our microelectrodes have values lower than theirs so that we need not care about the change so seriously. Of course, we must be careful, when electrodes with resistances of more than $10 \mathrm{M} \Omega$ were used. Anodic (or cathodic) pulses of 25 to $40 \mathrm{msec}$., with the peak value of $10^{-8 \mathrm{~A}}$, were applied. There was no significant difference between anodic and cathodic subthreshold current less than a certain values, as for the measurement of the membrane resistance. When repeated pulses were applied, the frequency 
was set at 20 cycles per second. When a single pulse was chosen, it was interposed to the various phases of the AP by a delay circuit. When the membrane resistance of a resting state was studied, the drive stimulus was stopped.

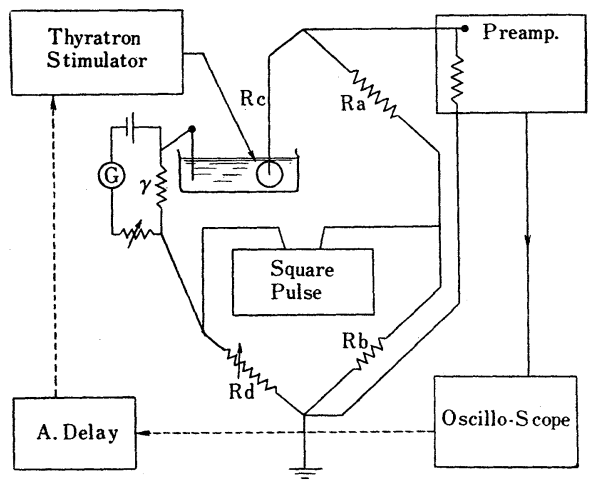

FIG. 9. Bridge circuit, used for the measurement of the membrane resistance.

$\mathrm{Ra}: \mathrm{Rb}(100 \mathrm{M} \Omega: 10 \mathrm{~K} \Omega$, or $10 \mathrm{M} \Omega$ : $1 \mathrm{~K} \Omega$ )

Rc: Microelectrode

Rd: Variohm

G: Galvanometer

r: $100 \Omega$ : Compensation circuit

In this circuit, the vessel was shown to have a leak parallel to the variohm, which ranged from $1.5 \mathrm{M} \Omega$ to $600 \mathrm{~K} \Omega$. Attention must be paid for this as our experimental errors, but the value is so large that it can be neglected compared with the variohm. Impalement of microelectrode sometimes produces an increase of electrode resistance. Hence, it is impossible to calculate the absolute value of the membrane resistance. However, when the electrode resistance does not vary so much, the relative comparison of the injured part, or the resting and action phase can possibly be permitted, especially in the case of a qualitative treatment of the data. Thus experiments were devised as follows. Firstly, trying to balance the bridge by controlling the variohm, the rectangular pulse was monitored on the oscilloscope. When the balanced point of a variohm showed $R_{1}$ before impalement, the electrode resistance $x$ is calculated from the next formula :

$$
\frac{x}{10}=\frac{R_{2}}{1,000} .
$$

After impalement, the variohm is readjusted and the balanced value is recorded as $R_{2}$. Then, the membrane resistance $y$ is calculated as follows,

$$
\frac{x+y}{10}=\frac{R_{2}}{1,000}
$$

Therefore,

$$
y=\frac{10}{1,000} R_{2}-\frac{10}{1,000} R_{1} .
$$

From this formula, the resistance of the injured cells, the normal cells and the intermediate cells, which are indefinite, whether normal or not, were measured respectively. The frequency distribution curve became as shown in fig. 10 . 
From this graph, the injured cells were proved to exhibit generally a lower resistance than the normal cells.

\section{Excitability changes}

By an intracellular cathodal stimulation, higher thresholds were obtained in the injured cells than in the normal cells. Strength-duration curves of the cells are shown in the graph of fig. 11. In the injured cells, the hyperbolic relation was not always obtained as seen in the typical case of the normal cell. The curves indicated a trend to shift to the right upper part.

Refractorieness was studied thereafter by the impalement of two microelectrodes (electrode-distance: 50 micra),

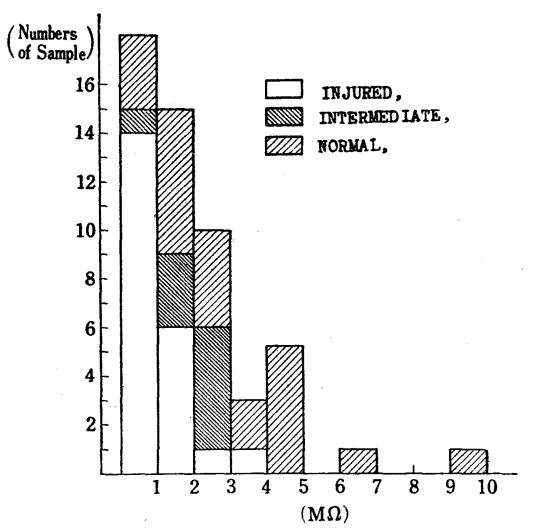

FIG. 10. The distribution curve of the membrane resistance for the injured, the intermediate and the normal cells. the one for stimulation and the other for recording. Each case showed a prolonged absolute refractory period, for it was proved to be later than $80 \%$-repolarisation, whereas the normal absolute refractory period lay between 60 to $70 \%$ repolarisation (20).

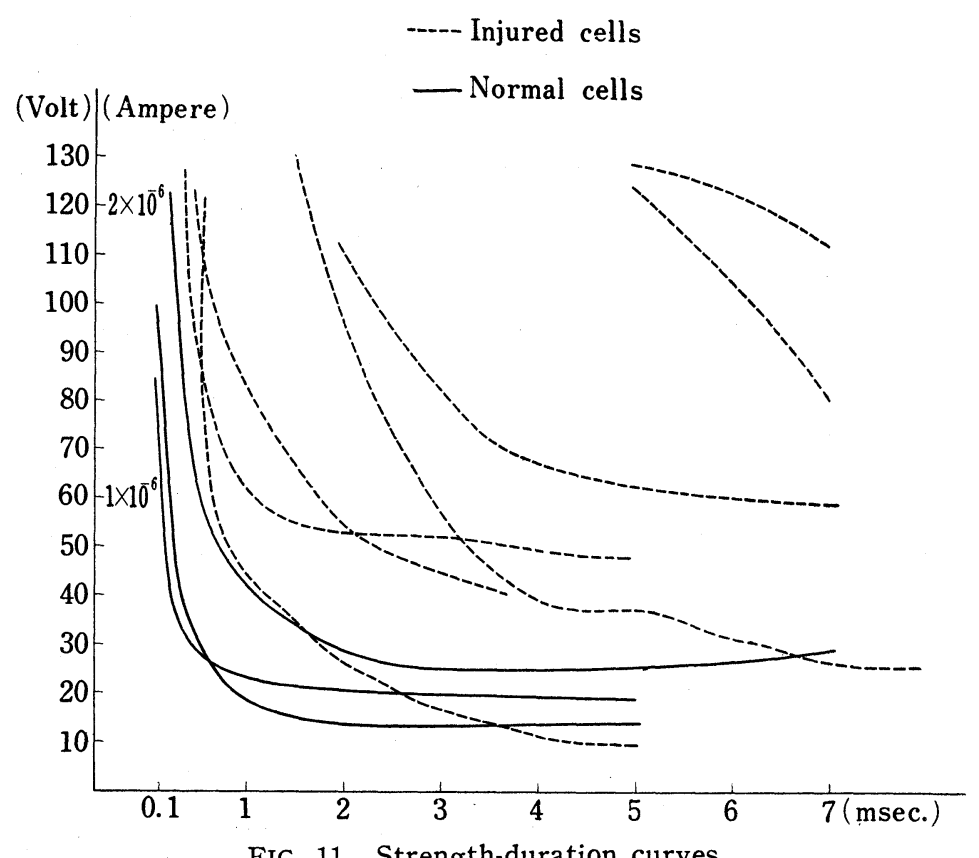

FIG. 11. Strength-duration curves. 


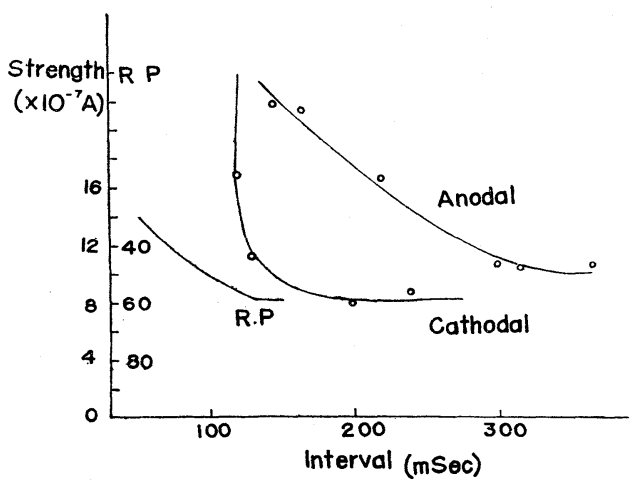

FIG. 12. Strength-interval curves. Two electrodes with a distance of $50 \mu$ were inserted into one cell and the data were obtained. The left lower curve is a time course of the repolarisation of the injured cell.

DISCUSSION

Injuries were localized, but not so sharply edged, for the cells in the margin of the sharp injury tend to recover its height of RP, within 10 minutes or so as already shown by Weidmann with Purkinje fibers (14). However in this study, the purpose was not to see the recovery process, but to test the various injured states. So the injury, not so sharply localized, was applied, with an intention of maintaining the injured state fully. The demarcation of the injured region from the normal one, and the recovery of the heart muscle fragment had been pointed out already by Cranefield (21) and Rothschuh (22). These characters made it possible to use the excised heart muscle as an experimental preparation. According to Sugi (23), impalement of a microelectrode itself causes an inevitable injury, but now I do not attempt to discuss into this general problems.

The data showed, that injured cells had lower RP and membrane resistance compared with the normal cells. AP was characterised by low OS, slow rise velocity and "Plateau-Verlust". The latter fact corresponds also to the $\mathrm{O}_{2}$ defficient state. Meanwhile the short period of hyperpolarization did not cause the recovery and it was supposed, that the recovery might need more hours for completion. These two facts make us remind, that the metabolic process might be influenced by injury. If we interprete the excitatory process by Hodgkin's sodium theory, the lowered RP in the case of injury is explained by a decreased $P_{\mathrm{K}}$ and an increased $P_{\mathrm{Na}}$ (each $P$ is respectively a permeability constant for potassium or sodium). In the normal cell, $P_{K}$ is far greater than $\mathrm{P}_{\mathrm{Na}}$. Therefore if we take the ratio $\frac{P_{\mathrm{K}}}{P_{\mathrm{Na}}}$, the following will be established,

$$
1<\left(\frac{P_{\mathrm{K}}}{P_{\mathrm{Na}}}\right) \text { injured }<\left(\frac{P_{\mathrm{K}}}{P_{\mathrm{Na}}}\right) \text { normal. }
$$

In fact, the loss of $\mathrm{K}$ and the increase of $\mathrm{Na}$ in the injured nerve cell had been proved experimentally by Harreveld and Russel (24). At the upstroke or depolarisation phase, $P_{\mathrm{Na}}$ is greatly diminished when injured. At the plateau or repolarisation phase, we cannot predict the relation of $P$ exactly. This 
means, that the biological membrane loses the ability of selective permeabilities for ions when injured.

The relation between permeability and resistance has not been studied quantitatively, but generally speaking permeability is considered to be inversely proportional to electrical resistance. In our examples, the lowered selective permeability for ions is not combined with the lowered $P$ value, for the low resistance corresponds to the high $P$ constant. Thus it is reasonable that the lowered selective power accompanies high value of $P$. After all, both the decreased electrical resistance and selective permeabilities for ions suggest us that each ion species leaks more easily through the membrane, when injured, than in the case of the control. In the former cases, it is easily considered, that the cellular excitability, considered from the standpoint of the electrical threshold, may be lowered. This was exemplified directly by the intracellular stimulation. It is well known, that excitability of the cut end of the nerve is low in the nerve-muscle preparation, and the part of the nerve nearest the muscle remains excitable the longest. Sometimes this is called the law of Ritter-Valli (25). In the cardiac muscle also excitability of the cells near the injured part becomes lowered, while the distant cells undergo the less injured effect and maintain the normal excitability for a longer period. The speed of recovery is slowest at the injured margin, and vice versa. In other words, the law of the nerve-muscle preparation is applied to the cardiac muscle block, under a slight modification.

These injured cells obey the all or none law, but the effect of injury does not follow the all or none law and many graded AP's appear around the injured region. When the degree of injury exceeds over a certain limit, the cells do not recover any more.

\section{SUMMARY}

The cellular membrane potential of the injured cardiac muscle fiber of the dog was recorded, and its various electrical properties were investigated.

(1) Injury was caused by either of a mechanical compression with a glass tube, burn, and a ligature with a thread. The injured region was unable to impale, but the cells around there could be examined, and showed diminished $\mathrm{RP}$, rise velocity decrease or disappearance of OS of AP. The greater the distance from injury, the less was the degree of impairment.

(2) A short period of hyperpolarization altered neither OS nor rise velocity.

(3) Membrane resistance of the injured cells decreased remarkably.

(4) By injury the threshold (rheobase) was elevated to a higher level as shown in the strengh-duration curves. Absolute refractory period was prolonged until a later phase of more than $80 \%$ repolarisation.

(5) There findings were discussed and the author would interprete as follows: the injured membrane loses its ion-selective ability and becomes leaky to ions.

The author wishes to acknowledge the encouragement and criticism of Prof. Kojiro Matsuda, and the help of Drs. Hoshi, Hayashi, Atsumi, Hashimoto and Mr. Hirosawa for this investigation. 


\section{REFERENCES}

1. ScнüтZ, E. Einphasische Aktionsströme von in situ durchbluteten Säugetierherzen. Z. f. Biol. 92: 441, 1932.

2. Jochim, K., KATZ, L. N. AND MAYNE, W. The monophasic electrogram obtained from the mammalian heart. Am. J. of Physiol. 111: 177, 1935.

3. LING, G. AND GERARD, R. W. The normal membrane potential of frog sartorius fibers. J. cell. comp. Physiol. 34 : 383, 1949.

4. Weidmann, S. Elektrophysiologie der Herz-muskelfaser. Bern: Stuttgart. Huber, 1956.

5. Brooks, C. MCC., Hoffman, B. F., Suckling, E. E. ANd ORIAS, O. Excitability of the heart. New York: Grune and Stratton, 1955.

6. Trautwein, W. und Dudel, J. Aktionpotential und Mechanogram des Katzenpapillarmuskels als Funktion der Temperatur. Pfï̈g. Arch. 260: 104, 1954.

7. Woodbury, L. A., Woodbury, J. W. AND Hecht, H. H. Membrane resting and action potentials from cardiac muscle fibers. Circulation 1: 264, 1950.

8. Matsuda, K., Hoshi, T. And Kameyama, S. Cellular Potentials of Normal Mammalian Ventricle. Medical Science 7:379, 1956.

9. SANO, T. Electrocardiograms obtained by capillary ultramicroelectrodes on the surface of the heart in situ, analysis of cardiac functions in its physiological and pathological conditions (II). Jap. Circul. J. $20: 1$ (No. 8), 1956 (in Japanese).

10. Cranefield, F. P. AND Hoffman, B. F. Electrophysiology of single cardiac cells. Phvsiol. Rev. 38 : 41, 1958.

11. Ueda, G., Hoshi, T. AND Hayashi, S. Cardiac Injury and Cellular Potentials. The 35th Jap. Physiol. Congress.

12. Matsuda, K., Hoshi, T., Kameyama, S., Kusakari, H. and Sakurai, K. Ventricular membrane potential of the dog surviving long exposure to low temperature. Medical Science 9: 21, 1958 (in Japanese).

13. Hoshi, T. A new simple method for filling the microelectrodes with electrolyte solution. Medical Science 8: 175, 1957 (in Japanese).

14. Sakurai, T., Hoshi, T., Kameyama, S. and Matsuo, M. Electronic circuit for studying cardiac membrane potential. Medical Science 7: 439, 1956 (in Japanese).

15. WeIDMANN, S. Elektrophysiologie der Herzmuskelfaser, translated by Matsuda, K., p. 28, p. 66. Tokyo: Kinpodo, 1957 (in Japanese).

16. BURGER, H. C. A theoretical elucidation of the notion "ventricular gradient". Am. Heart J. $37:$ 240, 1957.

17. TANAKA, I. AND YamanaKa, T. The resistance of the intracellular microelectrode. Science (Kagaku) $27: 255,1958$ (in Japanese).

18. Osterhout, W. J. V. Injury, Recovery and Death, in relation to conductivity and permeability. Lippincott Company, 1922.

19. YAMANAKA, T. Electrophysiological investigations of cardiac muscle fibers of Toad with superfine microelectrode. Part I. On the resting and action potentials. Part II. On the changes in the membrane resistance during activity. J. of Tokyo Women's Med. Coll. $27: 520,1957 ; 28: 507,1958$ (in Japanese).

20. MAtsuda, K. ET $A L$. On the recovery of the heart muscle excitability. The 35th Jap. Physiol. Congress. J. of Physiol. Soc. of Japan 20: 572, 1958 (in Japanese).

21. Cranefield, P. F., Eyster, J. A. E. ANd Gilson, W. E. Electrical characteristics of Injury Potentials. Am. J. Physiol. 167: 450, 1951.

22. RотнSснuн, K. E. Über den funktionellen Aufbau des Herzens aus elektrophysiologischen Elementen und Über Mechanismus der Erregungsleitung im Herzen. $P f$. Arch. 253: 238, 1951.

23. SugI, Y. On the microelectrode. Med. Science 4: 132, 1952 (in Japanese).

24. VAN HARREveld, A. AND RusSel, F. E. Ionic Migration in nerves. J. of Cell. and Comp. Physiol. $43:$ 355, 1954.

25. Evans, L. Principles of Human Physiology p. 185. London: Churchill, 1956. 